\title{
SUMMIT
}

VIENNA 2015

IS IS

\section{THE CONVERGENCE OF THE PHILOSOPHY AND SCIENCE OF INFORMATION}

\author{
Joseph Brenner \\ ${ }^{1}$ International Center for Transdisciplinary Research, Paris. c/o Chemin du Collège 1, 1865 Les \\ Diablerets, Switzerland \\ E-Mails: joe.brenner@bluewin.ch;
}

Tel.: +41-24-492-2118; Fax: +41-24-492-2118

Accepted:

\section{INTRODUCTION}

At the $4^{\text {th }}$ International Conference on the Foundations of Information Science 5 years ago, Professor Wu Kun of the Xi'An Jiaotong University in Xi'An, China published the first compendium in English of his work on the science and philosophy of information [1]. In particular, he indicated the central role of the Philosophy of Information (PI) and its impact on science and the Philosophy of Science (PS). This theory can now be usefully compared to the Philosophy of Information developed independently by Luciano Floridi in Europe [2].

At the $1^{\text {st }}$ International Conference on the Philosophy of Information held in Xi'An in October, 2013, Wu presented further work on the mutual impact of the PI on science and philosophy, which he describes as the scientification of philosophy and the philosophization of science. His view is echoed by the Dutch logician Pieter Adriaans who also has observed the major impact of information on philosophy itself. You have heard Professor Wu's presentation of his major themes in his opening talk for this $2^{\text {nd }}$ International Conference on PI. I will refer to them briefly below.

\section{POSITIONING THE PHILOSOPHIES OF SCIENCE AND INFORMATION}

There are today several attitudes, negative as well as positive, that be taken toward the statement that the Philosophy of Information is the locus of a revolution in philosophy and science. I accept it as a challenge to give ontological status to the changes in philosophy and the Philosophy of Science that might result from the incorporation of concepts from Information Science. However, major revisions in what philosophy and some parts of science are and how they evolve may have to become accepted.

\subsection{What is Science?}

The impact of information on science, via the Information and Communications Technologies (ICTs), is a complex process in which 'science' should not be viewed as a single discipline, and any impact will depend on what sciences are involved. I characterize two aspects of science: 1) its rough segmentation along the lines of 'hard' and 'soft', 
experimental and conceptual; and 2) the relative independence of different scientific disciplines of both types. It is a statement within the Philosophy of Science and of Information that what links the process, the pattern and the content of the sciences, including that of information itself, is their informational characteristics.

The concept of scientific method is only one of those meaningful in the contemporary practice of science. Computational methods can be and are applied routinely in all the sciences. In the human domain, it is the application of operative or organizational principles to an individual or social cognitive process to determine its dynamics, what 'forces are at work', that is essential for the determination of an informational commons.

\subsection{What is Information?}

Information is an entity or process, or set of entities and processes, that is unique in both science and philosophy. It requires acceptance as a concept that cannot be defined as an identity, but only as a dynamic interactive dualism of matter-energy (ontological properties) and meaning (epistemological properties). Cognitive processes, as well as their corresponding analyses and theories, instantiate similar dualities, of which the prime example is that of self and other.

Information is somehow associated with or constitutive of existence, but it has proven notoriously difficult to define and characterize, due to its multiple duality: it has both physical and apparently non-physical components, both a real dynamic and algorithmic descriptions. I note that both science and philosophy involve the observation of regularities in nature which only differ in the degree of certainty to which can be ascribed to them. Greater rigor in philosophy does not come easily; however, the properties of information common to both science and philosophy can be used to reconcile the physical, scientific properties of information with its epistemological, philosophical characteristics as a carrier of meaning. Both a physics (science) and mutually consistent philosophy of information are required and that both the philosophy and science of information must inform one another.

\section{SEMIOTICS}

Semiotics, the study of signs as categorizing linguistic entities and processes in the representation of meaning, has a position intermediate between the philosophy and science of information. It therefore has a role to play as a system of classification which complements the general things about the universe that we learn from some scientific facts about it. (The relation between Semiotics and Information Science will be discussed in detail at a separate Roundtable in this Conference stream).

Sören Brier argues [3] for a transdisciplinary framework where signs, meaning and interpretation are the foundational concepts within which information concepts have to function, and that C. S. Peirce's concept of semiosis creates such a new paradigmatic transdisciplinary framework. This semiotic doctrine, however, can be criticized as giving a more central role to signs as representations of reality than to the dynamic properties of reality itself.

Standard semiotic theory is particularly concerned with explicating higher-order concepts such as meaning, sign use, representation, language, intersubjectivity, etc., along with their interrelations. Cognitive Semiotics, as developed by Jordan Zlatev and others brings in empirical research which can both contribute to their explication and, at the same time, produce new insights. Cognitive Semiotics is thus less dependent on any particular semiotic theory. Its language remains more that of phenomenology than science, but it can be developed together with the transdisciplinary theories outlined below.

\section{THE CONVERGENCE OF SCIENCE AND PHILOSOPHY}

\subsection{Transdisciplinarity. Some New Theories}


In recent papers, Pedro Marijuan [4] has called for the transdisciplinary incorporation of insights from several sciences, an 'intertwining' of disciplines to enable further understanding of information and the foundations of information science. I argue that the Philosophy of Information can be included in this process as a consequence of the convergence of science and philosophy under the influence of information science, due to the properties of information itself.

From a philosophical perspective, what I consider the major recent advances in the philosophy of science, almost all are realist. Information processes are described as involving qualitative and quantitative changes in the amount and value of something irreducibly real in information.

- Terrence Deacon [5, 6]: information as 'absence'; from dynamics to teleodynamics;

- Luhn [7]: the causal-computational theory of information; embedding of the individual human being in an informational reality with a dual structure;

- Hofkirchner [8]: the re-ontologization involved in the different aspects of the informational revolution in progress;

- Brenner [9]: an extension of logic to real phenomena (Logic in Reality; LIR) that allows inferences about the energetic-ontological properties of information rather than truth-conditions.

A trend or tendency, e.g., toward the greater acceptance of non-standard logic in science, is not something that can be proven in 'hard' science. Nevertheless, if it is stated rigorously, a dialogue may be possible between the proponents and deniers of the trend. It is a corollary of LIR that both realist and anti-realist positions will always exist.

\subsection{Wu Kun and the Informational Turn}

$\mathrm{Wu}$ Kun has clearly brought out the ontological impact of information on philosophy. In his recent papers, Wu Kun presents detailed arguments for a new perspective on philosophy and science and the changes which they are undergoing under the influence of the informational activities of the society. I indicate here five position statements that constitute the 'backbone' of Wu's metaphilosophical theory [10]:

\section{- $\quad$ Mind - Matter Dichotomy}

With some notable exceptions, the bulk of philosophical doctrine is still based on the categorial separability of mind and matter. Despite advances in neurobiology and related sciences, the laws of reasoning and logic remain isolated from physical science, a part of semiotics as discussed above. Wu's first contribution to the discussion is to show that the existence of information requires a resegmentation of the existential field, making the mind-matter dichotomy on which much current thinking is still based untenable.

\section{- $\quad$ The Science - Philosophy Dichotomy}

The concomitant acceptance of the philosophical duality of information and the recognition of its physical duality abrogate any absolute separation between science and philosophy. This principle, within the Philosophy of Information (PI), is becoming applicable to science and consequently the Philosophy of Science (PS), as well as philosophy itself.

- The Position of Information in Reality. Properties

Any complex real entity, e.g., a person, can be considered as constituted by the totality of the informational processes, past, present and potential in which he is involved. The intermediate stages which bridge the gap between external and internal reality are all informational. This approach is consistent with Deacon's approach to the hierarchy of dynamics and second-order constraints necessary for the emergence of life.

- Implications for the Information Society 
$\mathrm{Wu}$ sees the multi-dimensional informational structures and processes in the society as reducing domination by central governmental control. They thus support an increase in principle in democracy, including information as a commons. Further work is needed, however, to determine if there is a direct correlation between the operative principles of Wu's Philosophy of Information and the political change necessary to implement them.

- The Informational Turn

As a discipline, Information Science has a unity by virtue of its spanning human knowledge from philosophy to science and engineering, with both vertical and horizontal relations between its component sub-disciplines. The further integration of Information Science and the Philosophy of Information implies a major Informational Turn in the current practice of both science and philosophy.

\section{CONCLUSION AND OUTLOOK}

In this paper, I have suggested that the unique dualism of information has ipso facto major implications for science and philosophy as a new form cognitive object that tends toward their mutual integration. In the conception of Wu Kun, this perspective of the 'scientification of philosophy' and the 'philosophization of science' is not intended to eliminate the specificity of both disciplines nor their individual development at a theoretical level, but requires the acceptance of the nonseparability of certain kinds of science and philosophy. The consequence may be an improved understanding the ethical and social level of a more logical approach, in the sense of relation to reality, to eventual resolution of on-going conflicts in the information society.

An urgent task, then, is to find new ways of correlating and organizing the insights obtained from the corresponding different perspectives, directed not toward some impossible unity but a new functional form of knowledge. The output of this Summit should be exemplary in combining method and content to begin to fulfill the promise of information.

\section{References}

1. Wu, K. 2010. The Basic Theory of the Philosophy of Information. Paper, $4^{\text {th }}$ International Conference on the Foundations of Information Science, August, Beijing.

2. Floridi, L. 2010. The Philosophy of Information. Oxford: Oxford University Press.

3. Brier, S. Cybersemiotics: Why Information is not Enough; University of Toronto Press: Toronto, Canada, 2008

4. Marijuan, P.C. The Uprising of the Informational: A New Way of Thinking in InformationScience. Presented at 1st International Conference in China on the Philosophy of Information, Xi'an, China, 18 October 2013.

5. Brenner, J.E. 2012. The Logical Dynamics of Information; Deacon's “Incomplete Nature". Information 2012, 3, 676-714

6. Deacon, T. W. 2012. Incomplete Nature. How Mind Evolved from Matter. New York: W. W. Norton \& Co.

7. Luhn, G. The Causal-Compositional Concept of Information Part I. Elementary Theory: From Decompositional Physics to Compositional Information. Information 2012, 3, 151-174

8. Hofkirchner, W. Emergent Information: A Unified Theory of Information Framework; World Scientific: Singapore, Singapore, 2013.

9. Brenner, J. E. 2013. Information: A Personal Synthesis. Information 2014, 5, 134-170;

10. Wu, K. 2013. The Development of Philosophy and its Fundamental Turn. Presented at $1^{\text {st }}$ International Conference in China on the Philosophy of Information, Xi'an, China, 18 October 2013. (Originally published in Journal of Humanity 5:1-6.)

11. Wu, K. and Brenner, J. E. 2014. The Informational Stance: Philosophy and Logic. Part II From Physics to Society. Logic and Logical Philosophy 23: 81-108.

(C) 2015 by the authors; licensee MDPI and ISIS. This abstract is distributed under the terms and conditions of the Creative Commons Attribution license. 